\title{
No increased injury incidence in the German Bundesliga after the SARS-CoV-2 virus lockdown
}

\author{
Werner Krutsch ${ }^{1} \cdot$ Abed Hadji $^{2} \cdot$ Tobias Trö $^{2} \cdot$ Dominik Szymski $^{1} \cdot$ Karen aus der Fünten ${ }^{2} \cdot$ Barbara Gärtner $^{3}$. \\ Volker Alt ${ }^{1} \cdot$ Tim Meyer $^{2}$
}

Received: 18 April 2021 / Accepted: 3 July 2021 / Published online: 20 July 2021

(c) The Author(s) 2021

\begin{abstract}
Introduction The coronavirus lockdown in 2020 resulted in a worldwide suspension of professional sports. The first major professional football league to restart after the lockdown was the German Bundesliga. This study investigates whether the injury incidence increased after the restart of the season with only 9 days of regular preparation time and without any friendly matches in comparison to three control periods.

Materials and methods In a prospective cohort study, injury analysis (at least 1 day of absence from official football matches or training sessions) of the German Bundesliga registry was standardised according to Hägglund et al. (Br J Sports Med 39:340-346, 2005) and Fuller et al. (Clin J Sports Med 16:97-106, 2006) for data collection and to previous publications for the validated use of media sources for injury registration. The study period after the lockdown in May and June of the 2019-2020 season was compared to three control periods: the period directly before the lockdown, the beginning of the 2019-2020 season and the 2018-2019 season final.

Results The nine match days after the restart of the 2019-2020 season showed an overall injury incidence of 4.9 per $1000 \mathrm{~h}$ football. This rate was significantly lower than that of the previous season final ( 9 last match days, overall injury incidence: 6.9 per $1000 \mathrm{~h}$ football; $p<0.001)$ and not increased compared to the rates after the summer break ( 9 match days; incidence: $5.5 / 1000 \mathrm{~h}, p>0.05$ ) or the winter break (8 match days; incidence: $5.6 / 1000 \mathrm{~h}, p>0.05$ ).

Conclusion The period after the unexpected break in the 2019-2020 season due to the coronavirus lockdown and the rapid return to competition showed no increase in the injury rate compared to the pre-lockdown period and a lower injury rate than in the previous season final. The unintentional mid-season rest with its potential for physical recovery and individual fitness training seems to have had a positive effect on injury occurrence.
\end{abstract}

Keywords Soccer $\cdot$ Pandemic $\cdot$ COVID-19 $\cdot$ Injury prevention

\section{Introduction}

The worldwide lockdown due to the coronavirus pandemic in March 2020 did not only affect all parts of social life but also suspended sporting activities including professional

Werner Krutsch

werner.krutsch@ukr.de

1 Department of Trauma Surgery, University Medical Centre Regensburg, Franz-Josef-Strauss-Allee 11, 93053 Regensburg, Germany

2 Institute of Sports and Preventive Medicine, Saarland University, Saarbrücken, Germany

3 Department of Medical Microbiology and Hygiene, Saarland University, Homburg, Germany football. The last pre-lockdown match of the 2019-2020 Bundesliga season took place on 11th March 2020. The season was restarted after 66 days and successfully finished within 42 days [24]. The interruption due to the coronavirus lockdown represented a psychologically and physiologically unique situation for the players. Contact restrictions during the lockdown as well as the implemented hygiene rules interfered with regular training schedules and prevented players from maintaining their normal level of sport-specific fitness.

Many sports medicine experts and practitioners did not believe in the feasibility of a quick restart of professional football [7] after the end of the lockdown period. Yet, the first three men's professional football leagues as well as the first women's league in Germany were restarted on the basis of a hygiene concept provided by an expert group of the 
German Football League (Deutsche Fussball Liga, DFL) and the German Football Association (Deutscher FussballBund, DFB). These hygiene standards - which are available online-mainly consist of a code of behaviour for players and staff, including social distancing, home quarantine, frequent PCR SARS-CoV-2 testing, frequent use of disinfectant and the consequent use of facial masks when not participating in sporting activities [17]. After permission from the German government, regular football training was possible again for the entire team from early May 2020 onwards [24].

One important question after the completion of the 2019-2020 season was whether the injury incidence would be influenced by the players' long absence from footballspecific training and match play and the short-term restart of the league with a tight schedule. Based on the knowledge that short-term changes or abrupt increases in training intensity facilitate severe knee injuries [23], the interruption of the season and the unusual preparation circumstances were suspected to increase severe knee and muscle injuries. Especially the lack of team training for many weeks and the short preparation phase before the first match were considered potential risk factors for severe injuries. Moreover, nine matches had to be played within 42 days, which represented an unfamiliar match load for many players. This constellation might have imposed a higher risk of muscle-tendinous injuries [9].

Therefore, this study investigated the incidence of football-related injuries for the period between the Bundesliga restart on 16th-17th May 2020 and the end of the season 42 days later. Possible changes in injury incidence are best assessed in a valid manner by means of a prospective injury survey, which-for obvious reasons-was impossible in this situation. However, a systematic injury registration was initiated in professional football in Germany 5 years ago. Publications based on this registry have already addressed various topics $[5,6,13,22]$. The current study investigated whether the period of 9 match days in 42 days between the restart and the completion of the 2019-2020 season in the men's first professional football league in Germany (Bundesliga) had a higher injury incidence than comparable time periods in previous football seasons.

\section{Methods}

This prospective cohort study investigated football injuries in the men's first professional league in Germany (Bundesliga) by means of media data obtained from a prospective national injury registry. The analysis only included injury types resulting in at least 1 day of absence from official football matches or training sessions [14]. All injuries sustained in training sessions and official club matches were included.

Injury data provided by medical staff and players as required for longitudinal studies are rarely available. Therefore, injury data for this study were prospectively documented in a standardised manner according to media analysis [14, 15, 22, 23, 27]. This analysis was mainly based upon data obtained from the German kicker ${ }^{\circledR}$ sports magazine, which is published twice a week and represents one of the main media sources about the first Bundesliga in Germany. Each professional football team has one specifically assigned journalist who updates team-specific information. Additionally, injuries were documented and analysed on a daily basis by screening the social media websites (Facebook ${ }^{\circledR}$ and Twitter ${ }^{\circledR}$ ) of each first league team and their players as well as on online platforms such as www.transfermarkt.de. Every documentation of an injury in the database was followed by a verification process, and each information was confirmed by at least one different source. According to international guidelines, injury diagnoses are best verified by medical staff $[14,15]$ as recently carried out by this study group $[3,5,19]$. In the current study, we used recently published standards for accurate injury registration by media analysis $[18,22,27]$ to confirm the validity of the media-based data (Table 1).

Injury types were categorised with regard to the affected body region, the type of injury and the time of occurrence during the season according to Fuller et al. $[14,15]$. The injury incidence was measured per 1000 football hours (h) of training, matches and overall exposure (training and match injuries combined). Official sports media provide valid information on the match exposure of all football players over the course of a season but not on their training exposure. For this reason, training exposure was estimated on the basis of previous

Table 1 Quality of media-based injury-specific and football-specific data of football players ( adapted from Krutsch et al. 2019 [22])

\begin{tabular}{lll}
\hline Type of information & Media-based information considered valid & Media-based information of questionable validity \\
\hline Injury pattern & Injured body region (particularly of severe injuries) & Type of injury (particularly of minor injuries) \\
Anthropometric data & Age, weight and height & - \\
Football exposure & Match exposure & Training exposure (good estimates are possible) \\
Injury details & Match and training injury, time of injury and affected leg & $\begin{array}{c}\text { Injury mechanism, contact or non-contact injury, } \\
\text { foul and concomitant injuries }\end{array}$ \\
\hline
\end{tabular}


publications by the authors in which the same study population was used in a different study period (seasons 2008-09 and 2009-10) as well as on the basis of the authors' own experience at professional football levels [3, $20,27]$. Based on these parameters, training exposure was calculated as an average of $7200 \mathrm{~h}$ per team per year and $340 \mathrm{~h}$ per player per year. The average match exposure amounted to $50 \mathrm{~h}$ per season. The study period consisting of the 9 match days between the Bundesliga restart and the end of the 2019-2020 season was compared to three other control periods: the last 9 match days of the 2018-2019 season, the 9 match days after the summer break at the beginning of the 2019-2020 season and the 8 match days after the winter break directly before the lockdown. Besides the overall injury incidence, we also focused on a detailed analysis of typical football injuries, i.e. ligamentous injuries to the knees and ankle joints, musculotendinous injuries to the thighs as well as head injuries.

\section{Statistical analysis}

Because all data on injuries and players were exclusively derived from publicly available media sources, this study did not have to be approved by an ethics committee. Continuous data are expressed as means \pm standard deviations (SD) and categorical data as frequency counts (percentages). Proportions between two groups were compared with the Fisher's exact test and continuous variables with the $t$ test. Incidence rates were compared with an exact test based on the Poisson distribution. The significance level was set at $p<0.05$ for the $\alpha$-error with $p<0.01$ considered 'highly significant'. All analyses were carried out with IBM SPSS Statistics, version 24.0 and R (version 3.3.3, The R Foundation for Statistical Computing).

\section{Results}

Overall, 787 injuries occurred during the 2019-2020 Bundesliga season (mean: 43.7 per season per team, overall injury incidence per $1000 \mathrm{~h}$ football exposure: 4.64). Mean age of the injured players was 25 years (SD 4.1; Table 2).

138 Injuries occurred in the nine remaining match days after the Bundesliga restart (26.5\% of all match days), amounting to $17.5 \%$ of all injuries in the 2019-2020 season. The body regions most frequently affected by injuries were the knee joints (16.7\%) followed by the ankle joints (15.9\%), the hip and groin region (13.0\%) and the thighs (11.6\%; Table 3). The most frequent types of injury were muscle injuries $(44.9 \%)$ as well as ligament and joint injuries (27.5\%). $65.2 \%$ of the injuries were sustained during training sessions (Table 3 ). The injury incidence in the different body regions after the Bundesliga restart showed a decreasing trend over the complete study period (Fig. 1).

The comparison of the injury incidences between the different periods of the season showed that the overall injury incidence was not higher after the restart than during the preliminary periods of the 2019-2020 season (Fig. 2). The injury incidence in the nine matches after the restart was 4.9 per $1000 \mathrm{~h}$ football exposure, which was significantly lower than the rate in the final nine match days of the 2018-2019 season (6.9 per $1000 \mathrm{~h} ; p=0.001)$. Similarly, the injury incidence in the 42 days after the restart was also not increased compared to the initial weeks after the start of the 2019-2020 season $(p=0.308)$ and after the winter break ( $p=0.287$; Fig. 2).

The incidence rates of muscle and head injuries were lower after the restart of the Bundesliga compared to any other time period. The incidence of knee injuries was similar during all investigated time periods. Only the incidence of ankle injuries was numerically higher after the restart than during either of the other three periods ( $p=0.89 ; 0.44 ; 0.24$, Table 4).

Table 2 Anthropometric data of the players and their playing position

\begin{tabular}{lllll}
\hline Anthropometric data & Mean & SD & Min & Max \\
\hline Age at injury (years) & 25.0 & 4.1 & 16.0 & 40.0 \\
Height $(\mathrm{cm})$ & 183 & 6 & 168 & 198 \\
Weight (kg) & 78.5 & 6.7 & 61 & 98 \\
\hline Playing position & & & $\%$ \\
\hline Keeper & & 36 & & 7.2 \\
Defender & 161 & & 32.4 \\
Midfielder & 194 & 39.0 \\
Striker & 106 & & 21.3 \\
\hline
\end{tabular}


Table 3 Injury profile in the German Bundesliga after the restart (body region, injury type, injury severity, match or training injury and others)

\begin{tabular}{|c|c|c|c|c|}
\hline Injured body region & Category & \multicolumn{2}{|c|}{$n(138)$} & $\%$ of total $(138)$ \\
\hline Head and neck & Head or face & \multicolumn{2}{|l|}{3} & 2.2 \\
\hline Upper limbs & Shoulder or clavicle & \multicolumn{2}{|l|}{1} & 0.7 \\
\hline \multirow[t]{2}{*}{ Trunk } & Sternum, rips or upper back & \multicolumn{2}{|c|}{6} & 4.4 \\
\hline & Lower back, pelvis or sacrum & \multicolumn{2}{|c|}{6} & 4.4 \\
\hline \multirow[t]{6}{*}{ Lower limbs } & Hip or groin & \multicolumn{2}{|c|}{18} & 13.0 \\
\hline & Thigh & \multicolumn{2}{|c|}{16} & 11.6 \\
\hline & Knee & \multicolumn{2}{|c|}{23} & 16.7 \\
\hline & Lower leg or Achilles tendon & \multicolumn{2}{|c|}{12} & 8.7 \\
\hline & Ankle & \multicolumn{2}{|c|}{22} & 15.9 \\
\hline & Foot or toe & \multicolumn{2}{|c|}{11} & 8.0 \\
\hline \multicolumn{2}{|l|}{ Others } & \multicolumn{2}{|c|}{20} & 14.5 \\
\hline Injury type & \multicolumn{2}{|l|}{ Category } & $n(138)$ & $\%$ of total (138) \\
\hline Fractures and bone stress & \multicolumn{2}{|l|}{ Fracture } & 4 & 2.9 \\
\hline Joint (non-bone) and ligament & \multicolumn{2}{|l|}{ Sprain or ligament injury } & 38 & 27.5 \\
\hline \multirow[t]{2}{*}{ Muscle and tendon } & \multicolumn{2}{|c|}{ Muscle rupture, tear, strain or cramps } & 62 & 44.9 \\
\hline & \multicolumn{2}{|c|}{ Tendon injury, rupture, tendinosis or bursitis } & 5 & 3.6 \\
\hline Contusions & \multicolumn{2}{|c|}{ Haematoma, contusion or bruise } & 27 & 19.6 \\
\hline Central or peripheral nervous system & \multicolumn{2}{|c|}{ Contusion (with or without loss of consciousness) } & 2 & 1.5 \\
\hline Injury severity & $n(1$ & & & $\%$ of total (138) \\
\hline Minor (1-3 days) & 26 & & & 18.8 \\
\hline Slight (4-7 days) & 26 & & & 18.8 \\
\hline Moderate (8-28 days) & 56 & & & 40.6 \\
\hline Severe ( $>28$ days) & 30 & & & 21.7 \\
\hline Time of injury & $n(138$ & & & $\%$ of total (138) \\
\hline Match injury & 48 & & & 34.8 \\
\hline Training injury & 90 & & & 65.2 \\
\hline
\end{tabular}

Fig. 1 Seasonal distribution of football-related injuries

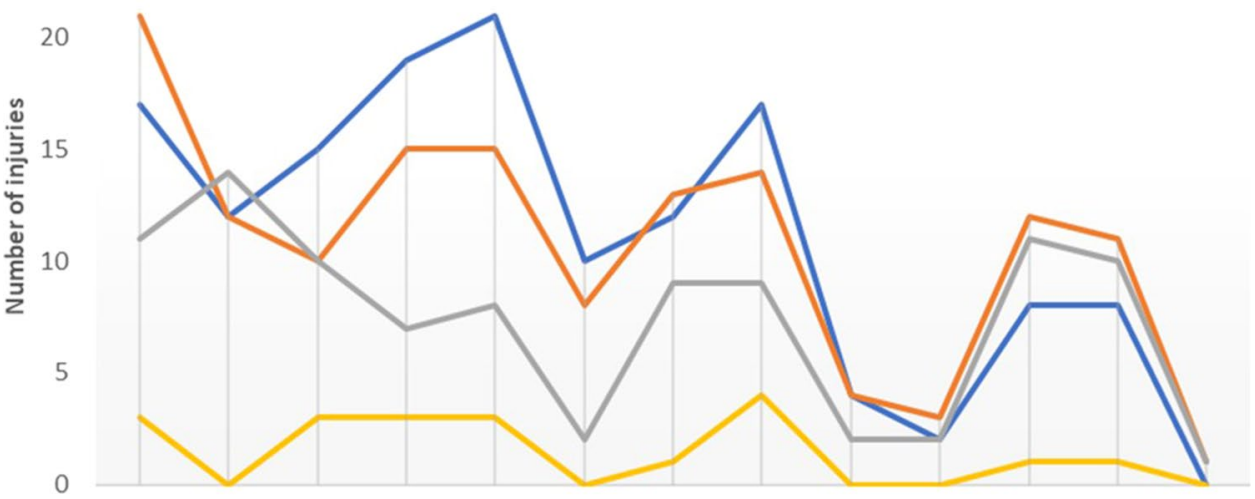

Jul 19 Aug 19 Sep 19 Oct 19 Nov 19 Dec 19 Jan 20 Feb 20 Mar 20 Apr 20 May 20 Jun 20 Jul 20 July 2019 to July 2020

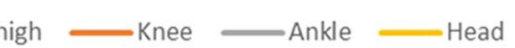


Fig. 2 Injury incidence after the restart compared to the rates of three previous seasonal periods

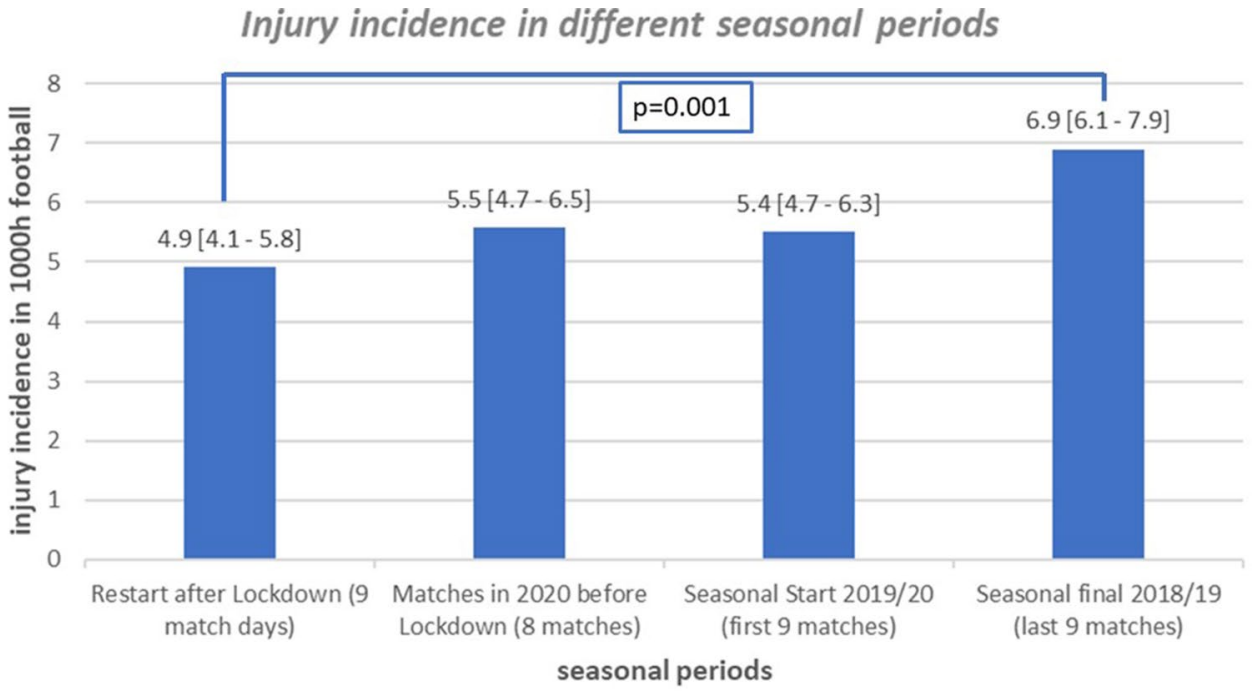

\section{Discussion}

For the first time, this study provides data on the impact of the coronavirus pandemic and its associated interruption of training and competition on the injury incidence in professional football. This study compared prospectively collected injury data on the first men's professional football league in Germany (Bundesliga) obtained from media analysis before and after the lockdown. The nine remaining matches of the 2019-2020 season final played within 6 weeks in May and June 2020 showed significantly fewer injuries than the nine matches of the 2018-2019 season final. The unexpected break in the 2019-2020 season and the rapid return to competition of the first professional sports league worldwide [24], which was controversially discussed before and after the restart, had no negative effect on injury occurrence.

With regard to injury prevention, the time between the restart of team training and matches after the ease of the very strict lockdown restrictions was probably a highly relevant period. None of the 18 Bundesliga teams was allowed to participate in friendly matches with other teams-usually an integral part of pre-seasonal preparation-before the restart of the season. Therefore, the teams had less opportunity of preparing themselves for highly competitive, football-specific, on-field movements or tactics. In terms of injury prevention, practising football-specific movements in competition-like circumstances is deemed crucial [1, 21]. A further aspect to consider is the content of training sessions, and the very short time span between resuming full team training and the start of the nine remaining matches presented a challenge in this regard. According to previous research, short-term changes such as a sudden move to another club, replacement of the coach or relegation to a higher league [23] influence training contents; such influences or just an abrupt start of the season may increase the risk of sustaining some types of football injuries. However, this study does not provide indications for any significant increase in injury incidences after the lockdown and the rapid return to competition.

The unexpected reduction in the injury incidence gives rise to controversial discussions and speculations about the underlying reasons. The players did not completely stop training during the lockdown. Training continued on an individual basis and consisted of endurance, strength and conditioning elements. For some players, the lockdown period may have represented a chance to recover from a long-lasting overuse injury or to cure a minor injury, which may have subsequently led to a major injury. Also, preventive training may have been conducted more frequently and on a more individualised basis than in regular seasons. The decreased injury rate after the Bundesliga restart may have been also based on improved healing processes during the lockdown. This unique situation possibly gave injured tissue adequate time to heal and players the time for structured rehabilitation before their return-to-play [10, 25, 26], which is usually not possible amidst a professional football season. Therefore, previously injured players were able to start playing football with less overuse complaints. Such minor complaints are a risk factor for sustaining more severe injuries to the knees or the ankles [19], and the absence of such injuries led to high match availability after the restart and ultimately maybe to fitter players.

This prospective study showed that the injury incidence after the restart after a much longer mid-season absence from playing football than usual was not higher than in the control periods, i.e. the first few weeks of the 2019-2020 season or the weeks directly before the lockdown. This finding also holds true with regard to muscle injuries that tend to occur more often in case of insufficient fitness or during a tight match schedule $[8,9]$ such as after the restart 


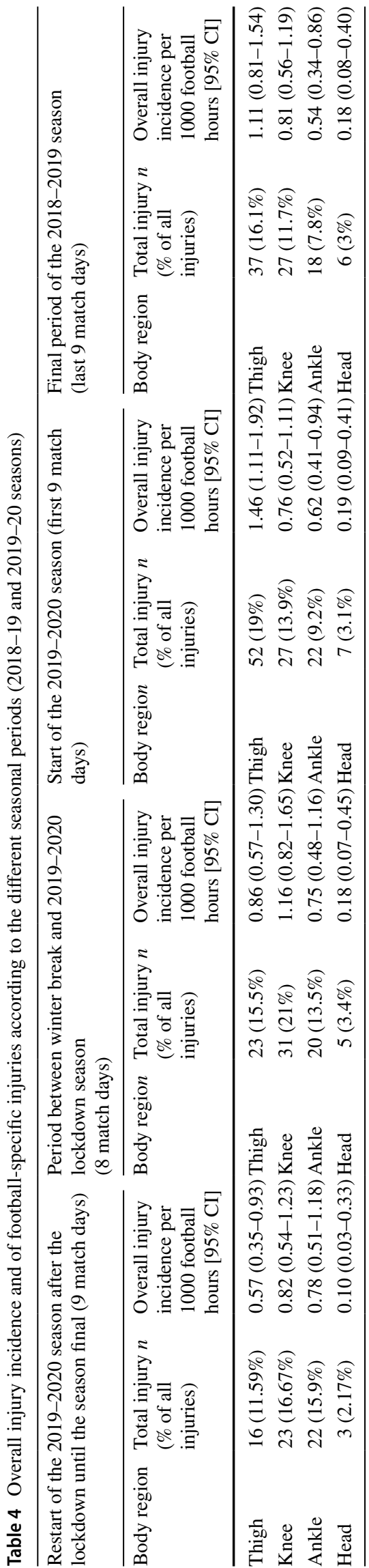

with 9 matches in 6 weeks. The somewhat unprepared rapid restart of match play, which depended upon political regulations, made it impossible for the clubs to follow traditional seasonal preparation concepts. Because such short-term increases in psychological and physical stress are wellknown factors for sustaining injuries, especially knee injuries [2,23], this aspect was a major concern before and after the restart. Additionally, the control period of the final weeks of the previous 2018-2019 season showed a higher injury incidence than the 2019-2020 season final after the lockdown. Whether the lower injury incidence in head injuries after the restart was influenced by a lower rate of physical contacts due to a lower frequency of contact duels is speculative and cannot be answered finally. This question should be answered in further investigations based on the video analysis of players' behaviour and the frequency of contacts or heading duels.

The findings of this study may have an important impact on injury primary, secondary and tertiary prevention strategies in professional football $[10,11]$. In comparison to recent studies on injury epidemiology in national professional football in Germany [3, 6, 13, 22], this study shows a comparable injury prevalence with more than $80 \%$ of the players and with comparably high injury incidence, especially on muscle and tendon injuries and on joint injuries of the lower extremities $[4,16,20]$. Despite increasing evidence of the efficacy of injury prevention measures and an increasing number of prevention strategies, longitudinal injury surveillance does not show any significant decrease in injury incidences [12]. One reason may be the slow transfer from research into practical routine, which is traditionally difficult to achieve in professional football [21] because time pressure and expectations on short-term success are more important than fundamental injury prevention requiring long-term commitment. Another aspect may be the lack of time for structured injury prevention measures and regeneration during regular seasons because of the tight match schedule or the pressure on teams, coaches and players. However, this study on the restart period after the corona lockdown may indicate that injury incidence can be reduced when football teams take the time for individual preparation strategies as part of primary injury prevention. Other debatable reasons for the lower injury incidence after the restart may be the increase in the number of substitutions from 3 to 5 per match implemented by the FIFA and a generally higher focus of football players on their professional activities because of the restrictions on social life during the pandemic.

\section{Limitations}

One potential limitation of this investigation is the reporting of injuries at the restart of the Bundesliga. The period after the lockdown differed to other seasonal periods: on 
the one hand, sports journalists were not allowed to follow their routine of being present at the clubs' training grounds on a daily basis. This absence may be a reason for a potential underreporting of injuries. On the other hand, professional football was the first professional sports to restart with political legitimation after the lockdown. Other professional sports were not allowed to restart, neither was the entertainment industry. This political legitimation increased the attention on Bundesliga football and subsequently on football injuries in the public and sports media and their daily reports about football clubs alike. Media-based injury registry may, therefore, be affected by the overreporting of injuries.

Media-based studies are associated with general limitations that may lead to imprecise injury statistics and debatable conclusions. However, injury reports provided by football clubs during the lockdown may also be invalid due to possible underreporting, but this lack is unlikely to have any impact because of the probably low number of injuries occurred during the lockdown. The current study population was evaluated by means of advanced national, regional and local media analyses with strict exclusion criteria. This media-based analysis was prospectively conducted over 5 years [22, 27], which improved injury recording because the most detailed information can be obtained immediately after the occurrence of an injury. Therefore, the strengths of our approach are the verification of the injury diagnosis by different public sources, its precisely defined methodology and our differentiation between valid and weak information (Table 1). These methods provide media-based data with high validity and represent a huge difference to other uncritically sampled and assessed media data about injuries also available in the scientific literature.

Because of the unexpected onset of the coronavirus pandemic, no other prospective study protocol could be implemented to compare injury occurrence before and after the lockdown. As the injury registration of this study was prospectively conducted for five seasons with constant methodology, the resulting injury incidence after the restart should be comparable to other periods of the present and previous seasons alike. The direct comparison of the 2019-2020 season final after the restart to the preceding 2018-2019 season final seems reasonable. Because of the lockdown break during the 2019-20 season, these two-time intervals differ significantly in physical preparation and also in a higher match frequency in a shorter period of time. Thus, the differences in the preparation before the last nine matches of the 2019-2020 season and the matches of the 2018-2019 season could be a reason for the significantly lower injury incidence. However, because the study period after the restart followed a longer break, we additionally used the periods after the summer and winter break as controls. Further investigations should follow based on our data. Especially the aspects fitness and training programmes during and after the lockdown may be important fields of research in the future.

\section{Conclusion}

The period after the unexpected break in the 2019-2020 Bundesliga season due to the coronavirus lockdown and the rapid return to competition showed no increase in the injury rate compared to the post-lockdown period and a lower injury rate than in the previous season final. The unintentional mid-season rest with the potential for physical recovery and individual fitness training seems to have had a positive effect on injury occurrence.

Funding Open Access funding enabled and organized by Projekt DEAL. No funding was received.

\section{Declarations}

Conflict of interest The authors report no conflict of interest.

Ethical approval Because all data on injuries and players were exclusively derived from publicly available media sources, this study did not have to be approved by an ethics committee.

Informed consent Not required.

Open Access This article is licensed under a Creative Commons Attribution 4.0 International License, which permits use, sharing, adaptation, distribution and reproduction in any medium or format, as long as you give appropriate credit to the original author(s) and the source, provide a link to the Creative Commons licence, and indicate if changes were made. The images or other third party material in this article are included in the article's Creative Commons licence, unless indicated otherwise in a credit line to the material. If material is not included in the article's Creative Commons licence and your intended use is not permitted by statutory regulation or exceeds the permitted use, you will need to obtain permission directly from the copyright holder. To view a copy of this licence, visit http://creativecommons.org/licenses/by/4.0/.

\section{References}

1. Alentorn-Geli E, Myer GD, Silvers HJ, Samitier G, Romero D, Lazaro-Haro C, Cugat R (2009) Prevention of non-contact anterior cruciate ligament injuries in soccer players. Part 1: mechanism of injury and underlying risk factors. Knee Surg Sports Traumatol Arthrosc 17:705-729. https://doi.org/10.1007/s00167-009-0813-1

2. Auer S, Kubowitsch S, Süß F, Renkawitz T, Krutsch W, Dendorfer $S$ (2020) Mental stress reduces performanceand changes musculoskeletal loading in football-related movements. Sci Med Footb. https://doi.org/10.1080/24733938.2020.1860253

3. der aus Fünten K, Faude O, Lensch J, Meyer T (2014) Injury characteristics in the German professional male soccer leagues after a shortened winter break. J Athl Train 49:786-793. https:// doi.org/10.4085/1062-6050-49.3.51 
4. Barengo NC, Meneses-Echávez JF, Ramírez-Vélez R, Cohen DD, Tovar G, Bautista JE (2014) The impact of the FIFA 11+ training program on injury prevention in football players: a systematic review. Int J Environ Res Public Health 11:11986-12000. https:// doi.org/10.3390/ijerph111111986.P

5. Beaudouin F, der aus Fünten K, Tröß T, Reinsberger C, Meyer T (2017) Head injuries in professional male football (soccer) over 13 years: $29 \%$ lower incidence rates after a rule change (red card). Br J Sports Med. https://doi.org/10.1136/bjsports-2016-097217

6. Beaudouin F, der aus Fünten KA, Tröß T, Reinsberger C, Meyer $\mathrm{T}$ (2019) Time trends of head injuries over multiple seasons in professional male football (Soccer). Sports Med Int Open 28:E6E11. https://doi.org/10.1055/a-0808-2551

7. Corsini A, Bisciotti GN, Eirale C, Volpi P (2020) Football cannot restart soon during the COVID-19 emergency! A critical perspective from the Italian experience and a call for action. Br J Sports Med 20:1186-1187. https://doi.org/10.1136/bjspo rts-2020-102306

8. Ekstrand J (2013) Keeping your top players on the pitch: the key to football medicine at a professional level. Br J Sports Med 47:723-724. https://doi.org/10.1136/bjsports-2013-092771

9. Ekstrand J, Hägglund M, Waldén M (2011) Epidemiology of muscle injuries in professional football (soccer). Am J Sports Med 39:1226-1232. https://doi.org/10.1177/0363546510395879

10. Ekstrand J, Krutsch W, Spreco A, van Zoest W, Roberts C, Meyer T, Bengtsson H (2019) Time before return to play for the most common injuries in professional football: a 16-year follow-up of the UEFA Elite Club Injury Study. Br J Sports Med 54:421-426. https://doi.org/10.1136/bjsports-2019-100666

11. Ekstrand J, Lundqvist D, Davison M, D'Hooghe M, Pensgaard AM (2019) Communication quality between the medical team and the head coach/manager is associated with injury burden and player availability in elite football clubs. Br J Sports Med 53:304-308. https://doi.org/10.1136/bjsports-2018-099411.E

12. Ekstrand J, Waldén M, Hägglund M (2016) Hamstring injuries have increased by $4 \%$ annually in men's professional football, since 2001: a 13-year longitudinal analysis of the UEFA Elite Club injury study. Br J Sports Med 50:731-737. https://doi.org/ 10.1136/bjsports-2015-095359

13. Faude O, Meyer T, Federspiel B, Kindermann W (2009) Injuries in elite German football—a media-based analysis. Dtsch Z Sportmed 60:139-144

14. Fuller CW, Ekstrand J, Junge A, Andersen TE, Bahr R, Dvorak J, Hägglund M, McCrory P, Meeuwisse WH (2006) Consensus statement on injury definitions and data collection procedures in studies of football (soccer) injuries. Clin J Sports Med 16:97-106. https://doi.org/10.1097/00042752-200603000-00003

15. Hägglund M, Waldén M, Bahr R, Ekstrand J (2005) Methods for epidemiological study of injuries to professional football players: developing the UEFA model. Br J Sports Med 39:340-346. https://doi.org/10.1136/bjsm.2005.018267

16. Hewett TE, Ford KR, Hoogenboom BJ, Myer GD (2010) Understanding and preventing ACL injuries: current biomechanical and epidemiologic considerations-update 2010. N Am J Sprts Phys Ther 5:234-251 (PMID: 21655382)

17. DFL Task Force Sportmedizin/Sonderspielbetrieb (2020) Konzept der Task Force Sportmedizin/Sonderspielbetrieb-version 4.0.
https://media.dfl.de/sites/2/2020/10/Anhang-I-zur-SpOL-TaskForce-Sportmedizin-Sonderspielbetrieb-Version-4.0-2020-1029-Stand.pdf. Accessed 13 Dec 2020

18. Krutsch V, Grechenig S, Loose O, Achenbach L, Zellner J, Striegel H, Alt V, Weber J, Braun M, Gerling S, Krutsch W (2020) Injury analysis in professional soccer by means of media reports-only severe injury types show high validity. Open Access J Sports Med 11:123-131. https://doi.org/10.2147/OAJSM.S251081

19. Krutsch W, Eder K, Krutsch V, Meyer T (2018) "Stay and play" in football: art of keeping players fit to play. Unfallchirurg 121:433440. https://doi.org/10.1007/s00113-018-0487-6

20. Krutsch W, Lehmann J, Jansen P, Angele P, Fellner B, Achenbach L, Krutsch V, Nerlich M, Alt V, Loose O (2019) Prevention of severe knee injuries in men's elite football by implementing specific training modules. Knee Surg Sports Traumatol Arthrosc 28:519-527. https://doi.org/10.1007/s00167-019-05706-w

21. Krutsch W, Loose O (2020) Total concept for prevention of severe knee injuries in competitive football. Arthroskopie 33:282-287. https://doi.org/10.1007/s00142-020-00390-2

22. Krutsch W, Memmel C, Krutsch V, Angele P, Tröß T, der ausr Fünten K, Meyer T (2019) High return to competition rate following ACL injury - a 10-year media-based epidemiological injury study in men's professional football. Eur J Sport Sci 18:1-9. https://doi.org/10.1080/17461391.2019.1648557

23. Krutsch W, Zeman F, Zellner J, Pfeifer C, Nerlich M, Angele $P$ (2016) Increase in ACL and PCL injuries after implementation of a new professional football league. Knee Surg Sports Traumatol Arthrosc 24:2271-2279. https://doi.org/10.1007/ s00167-014-3357-y

24. Meyer T, Mack D, Donde K, Harzer O, Krutsch W, Rössler A, Kimpel J, von Laer D, Gärtner BC (2020) Successful return to professional men's football (soccer) competition after the COVID-19 shutdown: a cohort study in the German Bundesliga. Br J Sports Med. https://doi.org/10.1136/bjsports-2020-103150 (Online ahead of print)

25. Tassignon B, Verschueren J, Delahunt E, Smith M, Vicenzino B, Verhagen E, Meeusen R (2019) Criteria-based return to sport decision-making following lateral ankle sprain injury: a systematic review and narrative synthesis. Sports Med 49:601-619. https://doi.org/10.1007/s40279-019-01071-3

26. Tol JL, Hamilton B, Eirale C, Muxart P, Jacobsen P, Whiteley R (2014) At return to play following hamstring injury the majority of professional football players have residual isokinetic deficits. Br J Sports Med 48:1364-1369. https://doi.org/10.1136/bjspo rts-2013-093016

27. Tröß T, der aus Fünten K, Hadji A, Beaudouin F, Meyer T (2020) Epidemiology of injuries in German Professional Football (soccer): a media-based prospective analysis over 5 consecutive seasons. Open Access J Sports Med 11:123-131

Publisher's Note Springer Nature remains neutral with regard to jurisdictional claims in published maps and institutional affiliations. 